\title{
ANALISIS PERUBAHAN TUTUPAN HUTAN DI TAMAN NASIONAL GUNUNG PALUNG MENGGUNAKAN PENGINDERAAN JAUH
}

\author{
(Analysis of Forest Cover Change in Gunung Palung National Park using Remote Sensing)
}

\author{
Nurul Ihsan Fawzi ${ }^{1,3 *}$, M. Ari Wibawanto ${ }^{2)}$, Mahardika Putra Purba ${ }^{1)}$ \\ ${ }^{1}$ Yayasan Alam Sehat Lestari, Jln. Sungai Mengkuang, Sukadana, Kalimantan Barat, Indonesia 78852 \\ ${ }^{2}$ Kementerian Lingkungan Hidup dan Kehutanan, Jln. Gatot Subroto No. 2, Jakarta, Indonesia 10270 \\ ${ }^{3}$ Tay Juhana Foundation, Jln. Rawa Bebek Utara No. 26, Jakarta, Indonesia 14440 \\ *e-mail: nurul.ihsan.f@mail.ugm.ac.id
}

\begin{abstract}
Monitoring forest cover to find out deforestation activities in a national park serves as an important task. This study aims to analyze forest cover changes in Gunung Palung National Park from 1989 to 2018. The method employs visual interpretation aided by supervised classification with the maximum likelihood method. Remote sensing data involved 18 Landsat images from 1989 to 2018 path/row 121/61. The results indicated that Gunung Palung National Park had 97,148 hectares of primary forest losing its $10 \%$ of its forest (since 1989). The primary forest decreased to 72,684 hectares in 1997 and 69,851 hectares in 2018. To date, primary forest cover has been found stable with secondary forests reaching to 25,050 hectares occupying $26 \%$ of Gunung Palung National Park area. Deforestation in Gunung Palung National Park was due to illegal logging and forest fires as a result of El Niño influence. The results of the analysis informed that there was an insignificant deforestation in Gunung Palung National Park during in the period of 2016 - 2018. In sum, conservation programs are encouraged to sustain, despite a decline in deforestation activities at Gunung Palung National Park.
\end{abstract}

Keywords: Gunung Palung National Park, forest conservation, deforestation

Abstrak

Monitoring tutupan hutan untuk mengetahui aktivitas deforestasi di taman nasional penting untuk dilakukan. Tujuan penelitian ini adalah untuk menganalisis perubahan tutupan hutan di TN Gunung Palung dari tahun 1989 - 2018. Metode yang digunakan adalah visual dibantu dengan klasifikasi terselia dengan metode maximum likelihood. Data penginderaan jauh yang digunakan adalah 18 citra Landsat tahun 1989 - 2018 path/row 121/61. Hasil penelitian menunjukkan sejak tahun 1989 TN Gunung Palung memiliki hutan primer seluas 97.148 hektar atau telah kehilangan 10\% hutannya. Luas hutan primer menurun menjadi 72.684 hektar di tahun 1997 dan menjadi 69.851 hektar ditahun 2018. Saat ini kondisi tutupan hutan primer dalam kondisi stabil dengan hutan sekunder mencapai 25.050 hektar atau 26\% dari luas TN Gunung Palung. Deforestasi di TN Gunung Palung disebabkan oleh pembalakan liar dan kebakaran hutan akibat pengaruh El Niño. Hasil analisis tidak ditemukan deforestasi di TN Gunung Palung selama rentang 2016 2018. Program konservasi harus tetap dilakukan walaupun telah terjadi penurunan aktivitas deforestasi di TN Gunung Palung.

Kata kunci: Taman Nasional Gunung Palung, konservasi hutan, deforestasi

\section{PENDAHULUAN}

Deforestasi menyebabkan hilangnya biodiversitas dan menyumbang emisi karbon ke atmosfer (Posa, 2011; Shvidenko, 2008). Sebanyak $1-1,2$ petagram (Pg) karbon per tahun diemisikan ke atmosfer akibat deforestasi hutan tropis atau 20\% dari total emisi global pertahun (Baccini et al., 2012; van der Werf et al., 2009). 
Pulau Kalimantan sebagai salah satu pulau terbesar di dunia dan sebagai paruparu dunia telah mengalami deforestasi yang cukup besar. Selama tahun 1973 2010, hutan di pulau Kalimantan telah hilang sebanyak $30,7 \%$ atau 123.941 $\mathrm{km}^{2}$ (Gaveau et al., 2013). Penyebab utama deforestasi ini adalah konversi menjadi perkebunan kelapa sawit (Tsujino et al., 2016). Penyebab lainnya adalah konversi ke lahan pertanian dan kebakaran hutan (Yoshikura et al., 2016a).

Dampak deforestasi terhadap lingkungan paling utama adalah biodiversitas di hutan yang telah ditebang. Sekitar $41 \%$ spesies tanaman dan hewan telah hilang dari hutan tropis yang telah rusak (Alroy, 2017). Kehilangan biodiversitas dan perubahan iklim menjadi ancaman utama akibat deforestasi yang terjadi. Perubahan iklim memicu suhu bumi semakin tinggi dan mengganggu pola curah hujan yang mengganggu produksi pertanian (Lawrence and Vandecar, 2015). Dampak lainnya pada lingkungan seperti banjir, kekeringan, peningkatan wabah malaria dan demam berdarah, dan peningkatan muka air laut menjadi permasalahan yang menyebabkan kerugian materiil dan immateriil.

Taman Nasional (TN) Gunung Palung berada di Kabupaten Kayong Utara dan Kabupaten Ketapang, Kalimantan Barat $\left(1^{\circ} 3^{\prime}-1^{\circ} 22^{\prime}\right.$ LU, $109^{\circ} 54^{\prime}$ - $110^{\circ} 28^{\prime}$ BT). Dengan luas 108.043 hektar, TN Gunung Palung menjadi rumah untuk 2.500 orangutan dan habitat pohon Dipterocarpaceae terbesar di Borneo (Johnson et al., 2005).
Sejak awal tahun 1990-an, TN Gunung Palung telah mengalami deforestasi maupun konversi ke lahan pertanian (Fawzi et al., 2018). Dalam rentang 1999-2004, 38\% hutan primer telah mengalami deforestasi (Curran et al., 2004). Penyebab utama deforestasi di TN Gunung Palung adalah pembalakan liar (illegal logging) yang terjadi pada awal tahun 2000-an, aktivitas pembukaan lahan baru untuk pertanian dan kebakaran hutan (Yoshikura et al., 2016b).

Monitoring tutupan hutan untuk mengetahui aktivitas deforestasi di taman nasional penting untuk dilakukan. Beberapa penelitian telah dilakukan untuk mengetahui tren perubahan tutupan hutan di TN Gunung Palung. Publikasi pertama dilakukan oleh Zamzani et al. (2009), di mana 18,7\% hutan primer telah terdeforestasi dalam rentang 1992 - 2004. Namun, Zamzani et al. (2009) hanya menghasilkan laju deforestasi sebesar 1,6\% pertahun tanpa peta distribusi perubahan tutupan hutan. Hal yang dilakukan oleh Tricahyono et al. (2016), hanya dengan menggunakan dua data citra Landsat 2005 dan 2012 menemukan TN Gunung Palung mengalami kehilangan hutan hanya seluas 1.122,21 hektar. Hasil yang hilang dalam Tricahyono et al. (2016) sangat kecil dibandingkan dengan penelitian yang dilakukan oleh peneliti lainnya, terutama Yoshikura et al. (2016b) dan Fawzi et al. (2018). Penelitian Tricahyono et al. (2016) tidak menjelaskan tentang pengaruh fenomena El Niño tahun 1997-1998 dan El Niño tahun 2015. Selain itu, beberapa 
penelitian juga tidak melakukan monitoring jangka panjang, sehingga tidak mampu menjelaskan variabilitas perubahan hutan yang terjadi. Seperti penelitian yang dilakukan oleh Curran et al. (2004), menjelaskan tentang detail perubahan tutupan hutan di TN Gunung Palung. Namun penjelasan tersebut hanya pada periode awal tahun 2000-an.

Monitoring tutupan hutan secara efektif dilakukan dengan metode in situ atau melalui survey lapangan. TN Gunung Palung dengan luas 108.043 hektar tidak memungkinkan untuk monitoring jangka panjang dengan metode in situ. Teknik penginderaan jauh adalah menjadi solusi utama untuk analisis perubahan tutupan hutan dan monitoring jangka panjang (Fawzi, 2016; Grecchi et al., 2017; Langner et al., 2012; Wang et al., 2010). Tujuan penelitian ini adalah untuk menganalisis perubahan tutupan hutan di TN Gunung Palung dari tahun 1989 - 2018. Hal ini menjadi penting untuk membuat keputusan tentang pengelolaan kawasan hutan yang lebih tepat sasaran.

\section{METODE PENELITIAN}

\section{Lokasi Penelitian}

Taman Nasional Gunung Palung berada di Kabupaten Kayong Utara dan Kabupaten Ketapang, Kalimantan Barat. TN Gunung Palung memiliki luas 108.043 hektar, dari sebelumnya 30.000 hektar ketika pertama kali dibentuk tahun 1937 (Setiawan and Sofian, 2018). TN Gunung Palung menjadi hutan untuk skema REDD ${ }^{+}$oleh Kementerian Lingkungan Hidup dan Kehutanan (Yoshikura et al., 2018).

Terdapat tujuh ekosistem hutan mulai dari hutan mangrove di pantai hingga hutan di daerah Gunung dengan ketinggian 1.016-meter diatas permukaan laut. TN Gunung Palung menjadi habitat bagi spesies satwa liar endemik orangutan (Pongo pygmaeus), bekantan (Nasalis larvatus), beruang madu (Helarctos malayanus), enggang gading (Rhinoplax vigil) dan macan dahan (Neofalis diardi). Selain spesies satwa liar endemik, terdapat sekitar $3.500-4.000$ jenis vegetasi berkayu di TN Gunung Palung yang telah teridentifikasi (Setiawan and Sofian, 2018). Sebagai habitat suku Dipterocarpaceae, ditemukan \pm 70 jenis pohon dari marga Anisoptera, Dipterocarpus, Hopea, Shorea, dan Vatica (Curran and Leighton, 2000). Saat ini, terdapat sekitar 57.245 orang yang berada di sekitar Kawasan TN Gunung Palung, yang bergantung pada fungsi hutan di Kawasan seperti kebutuhan air dan iklim lokal (BPS Kab. Kayong Utara, 2019). 


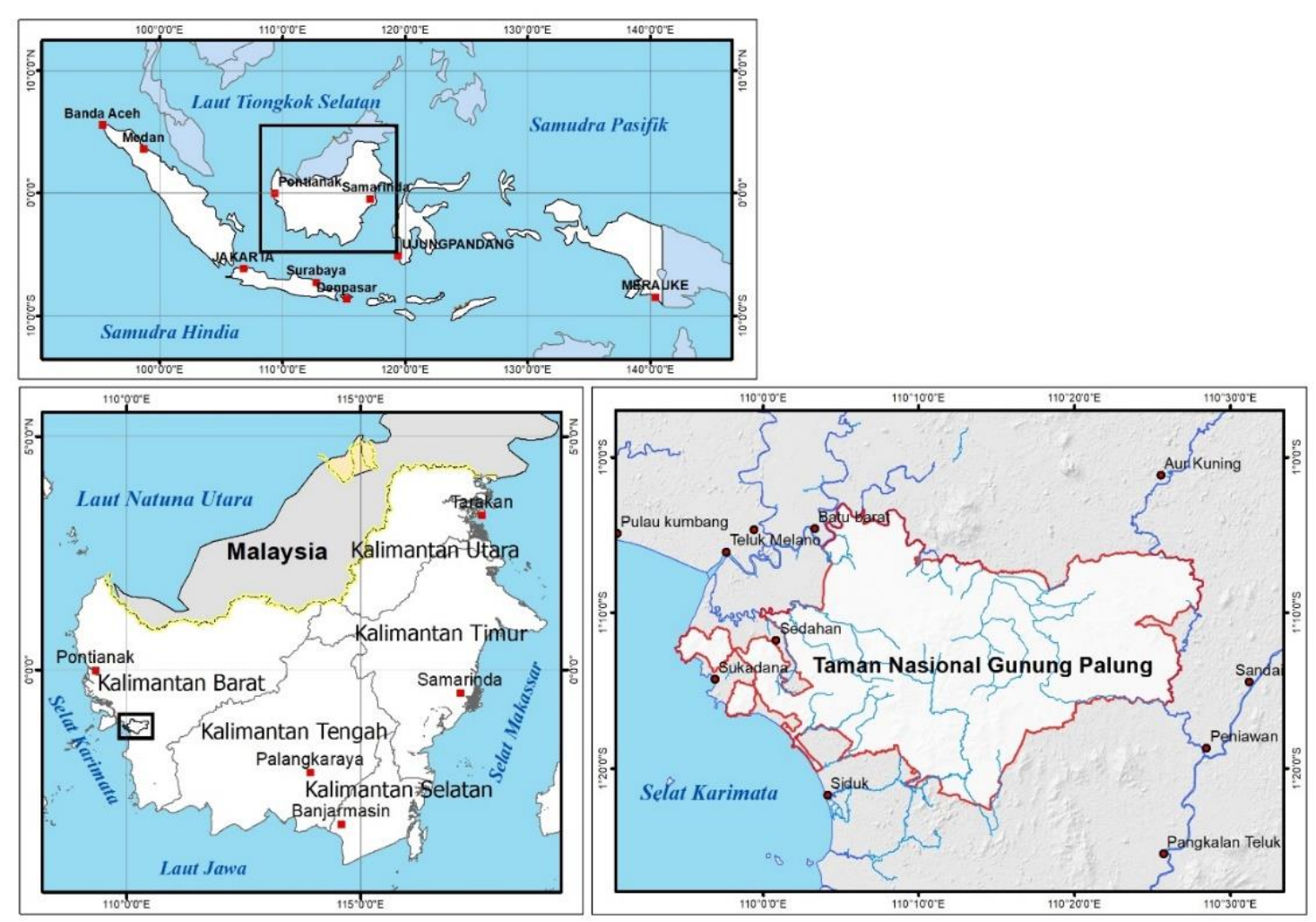

Gambar 1. Peta lokasi penelitian di Taman Nasional Gunung Palung, Kalimantan Barat. (The map of study location in Gunung Palung National Park, West Kalimantan).

\section{Data dan Analisis}

Data perubahan tutupan hutan didapatkan dengan interpretasi menggunakan 18 citra satelit Landsat path/row 121/61. Citra satelit Landsat yang digunakan yakni satelit Landsat 5 TM, Landsat $7 \mathrm{ETM}^{+}$dan Landsat 8 OLI. Citra tersebut memiliki resolusi spasial 30 meter dan telah terkoreksi geometrik (Loveland and Irons, 2016). Berikut adalah citra yang digunakan dalam penelitian ini.

1. Landsat TM perekaman tanggal 12 September 1989 dan 3 Oktober 1989.

2. Landsat TM perekaman tanggal 21 Juli 1997, 22 Agustus 1997 dan 28 Desember 1997.
3. Landsat $\mathrm{ETM}^{+}$perekaman tanggal 25 Juni 2002, 11 Juli 2002 dan 28 Agustus 2002

4. Landsat TM perekaman tanggal 7 Juli 2007.

5. Landsat perekaman tanggal 30 September 2011.

6. Landsat 8 perekaman tanggal 18 Agustus 2013

7. Landsat 8 perekaman tanggal 6 September 2014

8. Landsat 8 perekaman tanggal 7 Juli 2015

9. Landsat 8 perekaman tanggal 19 Maret dan 27 September 2016

10. Landsat 8 perekaman tanggal 22 Maret dan 14 September 2017 
11. Landsat 8 perekaman tanggal 15 Juli 2018

Analisis citra satelit menggunakan interpretasi visual dibantu dengan klasifikasi terselia dengan metode maximum likelihood (Hagner and Reese, 2007). Analisis menggunakan batas TN Gunung Palung sesuai Peraturan Menteri Lingkungan Hidup dan Kehutanan No. SK.733/Menhut-II/2014. Pengkelasan tutupan lahan menggunakan modifikasi dari Anderson et al. (1976), yaitu: (1) hutan montana, (2) hutan gambut, (3) hutan dataran rendah, (4) hutan mangrove, (5) hutan dataran rendah sekunder, (6) hutan montana sekunder, (7) hutan gambut sekunder, (8) secondgrowth hutan dataran rendah, (9) kebun masyarakat, (10) lahan pertanian, (11) ladang dan kebun, (12) permukiman, (13) hutan terdegradasi, and (14) lahan terbuka. Untuk memudahkan analisis, dari ke-14 kelas tersebut digolongkan dalam 4 klaster utama, yaitu: hutan primer (1-4), hutan sekunder (5-8), kebun masyarakat (8), lahan pertanian dan ladang (10-12), hutan terdegradasi (13), dan lahan terbuka (14).

Penentuan jenis hutan primer dan hutan sekunder menjadi hal penting dalam penelitian ini. Hutan primer didefinisikan sebagai hutan yang masih belum terjamah atau tutupan dari pohon kanopi (bukan sub-kanopi) diatas 90\%. Definisi ini untuk menghindari kesalahan klasifikasi menjadi hutan terdegradasi akibat satu atau dua pohon kanopi telah ditebang, tapi masih memberikan fungsi Ekosistem yang baik. Jika tutupan pohon kanopi 20 $90 \%$ didefinisikan hutan telah mengalami degradasi, dan jika kurang dari $20 \%$ telah terjadi deforestasi. Hutan yang tumbuh kembali dari hutan terdegradasi dikategorikan sebagai hutan sekunder "second-growth." Sedangkan hutan yang tumbuh kembali dari area yang terdeforestasi dikategorikan sebagai hutan sekunder. Ini untuk membedakan jenis hutan sekunder yang terbentuk dari dua proses regenerasi yang berbeda.

Hasil klasifikasi divalidasi dengan survey lapangan dan menggunakan citra resolusi tinggi SPOT 6. Survey lapangan dilakukan untuk mengetahui kondisi aktual dan mengetahui proses deforestasi yang terjadi. Indikator survey lapangan yang dilakukan adalah mengecek kondisi tutupan hutan menggunakan GPS dan mendata keberadaan penebang aktif di sekitar kawasan TN Gunung Palung.

\section{HASIL DAN PEMBAHASAN}

Hasil penelitian menujukkan bahwa hutan montana relatif tidak terjadi aktivitas penebangan hutan karena lokasi susah diakses dan kualitas kayu yang kurang bagus. Berbeda dengan jenis hutan lainnya, hutan rawa gambut telah mengalami deforestasi sejak tahun 1989 dan kehilangan 3.016 hektar. Ini akibat aktivitas perusahaan HPH yang menebang kayu di dalam Kawasan TN Gunung Palung.

Peningkatan aktivitas deforestasi terjadi di tahun 1997 (tabel 1) akibat kebakaran hutan dan tidak stabilnya kondisi politik di Indonesia. Faktor lainnya adalah fenomena El Niño yang menyebabkan kemarau panjang terjadi di Indonesia (Latif et al., 2017; Taufik et 
al., 2017). Lebih dari 9.409 hektar hutan telah terbuka dan 16.061 hektar mengalami degradasi. Dari 16.061 hektar, 15.921 hektar atau 99,1\% telah menjadi hutan sekunder, sisanya gagal terjadi regenerasi karena terbakar di musim panas setelahnya. Deforestasi terjadi di tahun-tahun berikutnya dengan intensitas kecil dibandingkan tahun 1997 dan 1989.

Perubahan tutupan hutan di TN Gunung Palung menurun pada periode 1997 - 2002. Deforestasi periode setelahnya menurun drastis jika dibandingkan dengan deforestasi yang terjadi pada tahun 1997. Menurunnya deforestasi berhubungan juga dengan penurunan aktivitas pembalakan liar. Hal ini berkontribusi terhadap regenerasi hutan yang terdegradasi atau terdeforestasi menjadi hutan sekunder. Walaupun telah terjadi regenerasi menjadi hutan sekunder, hutan sekunder yang terbentuk memiliki kompleksitas tanaman dibawah hutan primer. Bahkan, hutan sekunder dengan usia $16-18$ tahun memiliki komposisi dan struktur jauh dibawah hutan primer (Guariguata et al., 1997).

Tahun 2013, deforestasi yang terjadi akibat konversi menjadi lahan pertanian atau ladang. Deforestasi yang terakhir terjadi tahun 2015 akibat kebakaran hutan dan lahan (gambar 2). Kebakaran tersebut disebabkan musim kemarau yang panjang akibat El Niño. Kebakaran yang terjadi membuat kehilangan hutan primer seluas 1.914 hektar atau $\sim 1,7 \%$ dari total luas TN Gunung Palung. Lokasi hutan yang terbakar terletak di Matan - Srindit, Kubing, Pangkalan
Jihing, dan Tanjung Gunung. Dari 1.914 hektar yang terbakar, 1.197 hektar berubah menjadi padang rumput dan pakis yang membutuhkan untuk di restorasi, 37,5 ha digunakan untuk lahan pertanian yang terbakar akibat ladang berpindah, dan sisanya mengalami regenerasi alami.

Setelah kebakaran tahun 2015 tersebut, dalam rentang analisis data tahun 2016-2018 sudah tidak lagi terjadi deforestasi di TN Gunung Palung. Namun, TN Gunung Palung masih memiliki area seluas $\sim 5.100$ hektar berupa lahan terbuka yang harus direstorasi. Lahan terbuka tersebut yang didominasi oleh Imperata cylindrica dan Pteredium aquilinum memiliki dampak negatif terhadap ekosistem hutan karena mudah terbakar di musim kemarau (Kiyono and Hastaniah, 2000).

Secara singkat, sejak tahun 1989, TN Gunung Palung telah kehilangan hutan sebanyak $10 \%$ atau dengan hutan primer sebanyak $90 \%$ atau 97.148 hektar. Luas hutan menurun menjadi 72.684 hektar di tahun 1997 dan menjadi 69.851 hektar ditahun 2018. Saat ini kondisi tutupan hutan primer dalam kondisi stabil dengan hutan sekunder mencapai 25.050 hektar atau 26\% dari luas TN Gunung Palung. 
JURNAL TENGKAWANG (2020)

Vol. 10 (2): 75 - 88

Tabel 1. Statistik perubahan tutupan hutan di Taman Nasional Gunung Palung periode 1989 - 2018. (The statistic of forest cover change in Gunung Palung National Park in the period 1989 - 2018).

\begin{tabular}{|c|c|c|c|c|c|c|c|c|c|c|c|c|}
\hline No & Klasifikasi & 1989 & 1997 & 2002 & 2007 & 2011 & 2013 & 2014 & 2015 & 2016 & 2017 & 2018 \\
\hline 1 & Hutan montana & $22,126.8$ & $22,126.8$ & $22,126.8$ & $22,126.8$ & $22,126.8$ & $22,126.8$ & $22,126.8$ & $22,126.8$ & $22,126.8$ & $22,126.8$ & $22,126.8$ \\
\hline 2 & Hutan gambut & $20,862.7$ & $17,755.7$ & $17,751.9$ & $17,604.2$ & $17,486.0$ & $17,486.3$ & $17,480.3$ & $17,480.4$ & $16,960.1$ & $16,959.5$ & $16,959.3$ \\
\hline 3 & Hutan dataran rendah & $53,762.6$ & $32,405.5$ & $31,974.3$ & $31,173.3$ & $30,706.0$ & $30,654.1$ & $30,654.6$ & $30,654.8$ & $30,424.9$ & $30,424.6$ & $30,424.6$ \\
\hline 4 & Hutan mangrove & 395.6 & 395.6 & 395.6 & 382.7 & 382.7 & 382.7 & 375.5 & 375.5 & 339.9 & 339.9 & 339.9 \\
\hline 5 & Hutan dataran rendah sekunder & 0.0 & 279.1 & $4,319.9$ & $4,563.3$ & $5,147.0$ & $5,575.1$ & $5,590.6$ & $5,570.0$ & $5,401.6$ & $5,534.5$ & $5,650.5$ \\
\hline 6 & Hutan montana sekunder & 0.0 & 0.0 & 7.4 & 7.4 & 7.4 & 7.4 & 7.4 & 7.4 & 7.4 & 7.4 & 7.4 \\
\hline 7 & Hutan gambut sekunder & 0.0 & $2,346.1$ & $2,801.0$ & $3,354.9$ & $3,481.5$ & $3,483.2$ & $3,496.8$ & $3,510.9$ & $3,469.8$ & $3,470.1$ & $3,470.5$ \\
\hline 8 & $\begin{array}{l}\text { Second-growth hutan dataran } \\
\text { rendah }\end{array}$ & 0.0 & 55.6 & $15,182.8$ & $15,768.4$ & $15,767.9$ & $15,918.2$ & $15,918.0$ & $15,918.4$ & $15,918.8$ & $15,921.6$ & $15,921.2$ \\
\hline 9 & Kebun masyarakat & $2,853.2$ & $2,853.1$ & $3,755.4$ & $3,761.5$ & $3,818.4$ & $3,818.6$ & $3,818.7$ & $3,818.7$ & $3,781.8$ & $3,781.4$ & $3,781.0$ \\
\hline 10 & Lahan pertanian & 43.8 & 43.8 & 92.5 & 105.4 & 379.6 & 379.6 & 391.6 & 391.6 & 410.0 & 409.9 & 409.9 \\
\hline 11 & Ladang dan kebun & $4,508.3$ & $4,281.4$ & $3,487.9$ & $3,298.1$ & $3,698.9$ & $3,721.9$ & $3,721.9$ & $3,721.6$ & $3,826.3$ & $3,791.2$ & $3,791.6$ \\
\hline 12 & Pemukiman & 0.0 & 0.0 & 0.0 & 31.0 & 31.0 & 31.0 & 31.0 & 31.0 & 31.0 & 31.0 & 31.0 \\
\hline 13 & Degraded forest & 443.4 & $16,061.2$ & 814.7 & 0.0 & 0.0 & 0.0 & 0.0 & 0.0 & 0.0 & 0.0 & 0.0 \\
\hline \multirow[t]{2}{*}{14} & Scrub or open land & $3,016.3$ & $9,408.6$ & $5,302.4$ & $5,835.5$ & $4,979.4$ & $4,427.7$ & $4,399.6$ & $4,405.6$ & $5,314.3$ & $5,214.7$ & $5,098.8$ \\
\hline & TOTAL & $108,012.6$ & $108,012.6$ & $108,012.6$ & $108,012.6$ & $108,012.6$ & $108,012.6$ & $108,012.6$ & $108,012.6$ & $108,012.6$ & $108,012.6$ & $108,012.6$ \\
\hline
\end{tabular}


JURNAL TENGKAWANG (2020)

Vol. 10 (2): 75 - 88
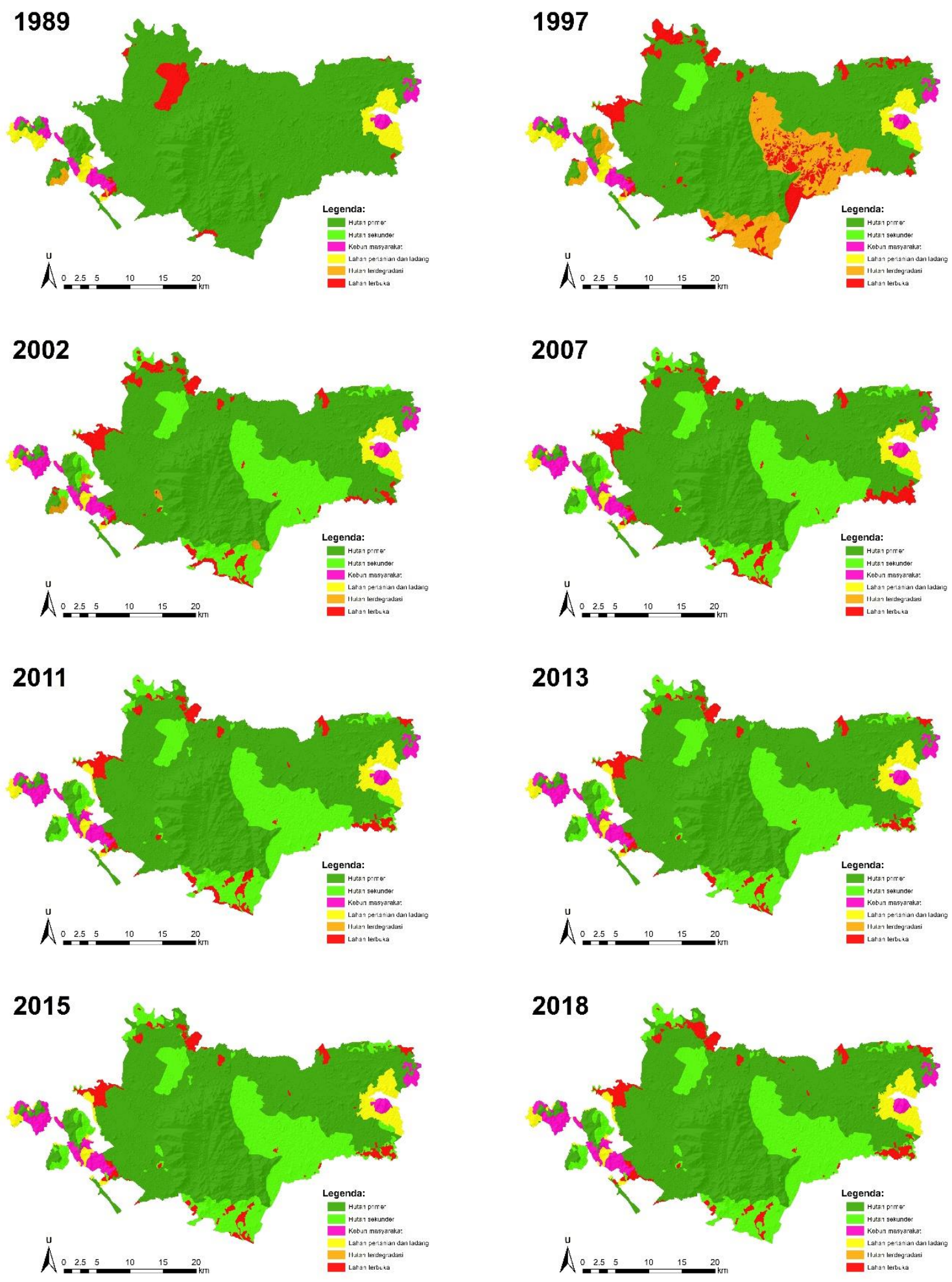

Gambar 2. Peta perubahan hutan di Taman Nasional Gunung Palung (The maps of forest cover changes in Gunung Palung National Park). 
JURNAL TENGKAWANG (2020)

Vol. 10 (2): 75 - 88

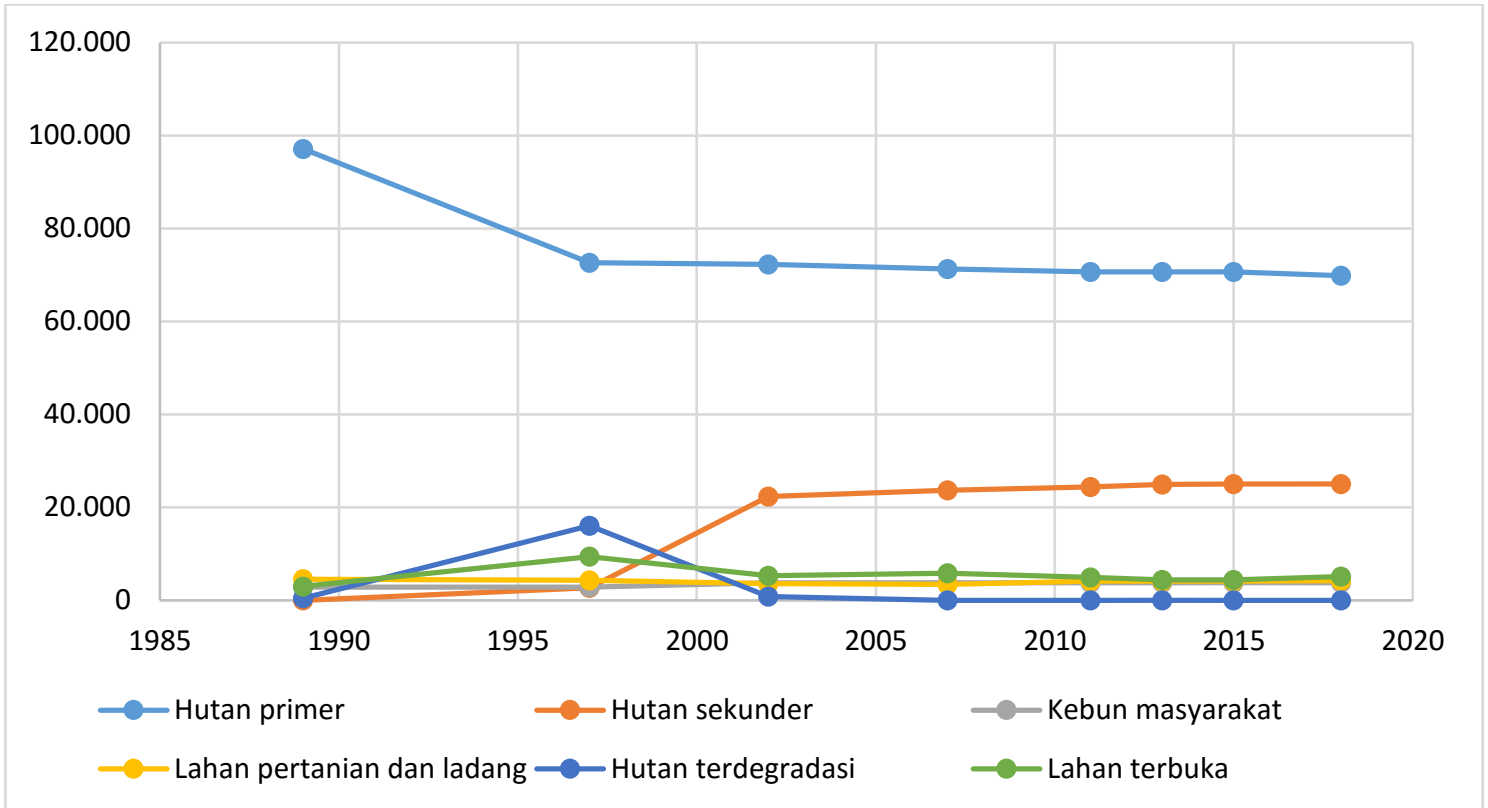

Gambar 3. Grafik fluktuasi perubahan hutan di Taman Nasional Gunung Palung (The graph of the fluxtuation of forest cover change in Gunung Palung National Park).

Dampak lingkungan dari perubahan hutan primer ke hutan sekunder atau lahan terbuka adalah perubahan biodiversitas tanaman hutan. Hilangnya pohon-pohon besar akibat deforestasi dan degradasi hutan akan membuat perubahan pola pembuahan massal yang juga akan mempengaruhi siklus reproduksi satwa liar (Phillips, 1997). Perubahan yang nyata adalah tumbuhnya spesies invasif Bellucia pentamera hampir di area hutan yang terdegradasi (Dillis et al., 2017). Aktivitas sosial ekonomi juga dapat terpengaruh dari dampak deforestasi yang menyebabkan banjir, kekeringan, atau perubahan suhu lokal (Fawzi and Iswari, 2019; van Dijk et al., 2009). Perubahan lingkungan akibat deforestasi juga dapat berdampak pada kesehatan manusia, terutama transmisi pathogen seperti penyakit malaria dan demam berdarah (Hammen and Settele, 2011; Patz et al., 2000).

Permasalahan dalam konservasi perlindungan hutan adalah melindungi hutan ini agar tidak ditebang dan terbakar ketika musim panas datang. Permasalahan kedua adalah bagaimana mengembalikan tutupan hutan yang telah terdeforestasi di TN Gunung Palung. Luas hutan yang perlu untuk direstorasi sebanyak $\sim 5.100$ hektar. Tantangan dari proses restorasi ini adalah terkendala oleh kebutuhan pendanaan yang cukup besar. Jika menggunakan kepadatan bibit 1.000 bibit per hektar, dibutuhkan sekitar 71 milyar rupiah untuk merestorasi seluruh kawasan TN Gunung Palung. Permasalahan terakhir adalah bagaimana menghentikan ladang berpindah atau aktivitas pertanian di dalam kawasan hutan.

Program konservasi berbasis solusi dan pemberdayaan masyarakat adalah metode paling tepat untuk melindungi hutan di TN Gunung Palung. Solusi di sini adalah dengan melibatkan masyarakat dalam pengelolaan hutan sebagai penerima manfaat utama (Webb 
et al., 2018). Pemberdayaan masyarakat harus terintregasi dengan penegakan hukum yang tetap menjadi solusi utama untuk pencegahan deforestasi. Sebagai contoh, bagaimana penegakan hukum para penebang yang telah tertangkap tidak memasukkan mereka dalam penjara, tapi bagaimana memberi mereka alternatif mata pencaharian yang lebih layak. Program UMKM yang telah dilakukan oleh Yayasan Alam Sehat Lestari (ASRI) dengan menukar gergaji mesin dengan mata pencaharian yang baru adalah contoh nyata dari solusi ini (Kubo et al., 2019).

Program konservasi harus tetap dilakukan walaupun telah terjadi penurunan aktivitas deforestasi di TN Gunung Palung. Hal ini untuk mendukung program Sustainable Development Goal (SDG, target pembangunan berkelanjutan) yang dicanangkan oleh Perserikatan Bangsa Bangsa. Salah satu tujuan SDG adalah bagaimana kita melindungi ekosistem hutan dan merestorasi hutan yang telah rusak untuk mencegah hilangnya keanekaragaman hayati (Swamy et al., 2018). Tujuan ini agar menjaga masyarakat disekitar hutan dapat memperoleh air bersih setiap hari dan terhindar dari dampak pemanasan global (Ellison et al., 2017). Intregasi faktor sosial dalam upaya perlindungan dan restorasi membuat deforestasi tidak terjadi di masa yang akan datang.

\section{KESIMPULAN}

Sejak tahun 1989, TN Gunung Palung telah kehilangan $10 \%$ dari hutannya. Deforestasi terjadi lebih besar pada tahun 1997 akibat kebakaran hutan yang dipicu oleh kemarau panjang akibat El Niño dan penebangan liar secara masif. Lebih dari 9.409 hektar hutan telah terbuka dan 16.061 hektar mengalami degradasi. Dari 16.061 hektar, 15.921 hektar atau 99,1\% telah menjadi hutan sekunder, sisanya gagal teregenerasi karena terbakar di musim panas setelahnya. Setelah terjadi deforestasi seluas 1.914 hektar di tahun 2015, tidak terjadi lagi deforestasi di tahun-tahun setelahnya. Saat ini, sebanyak $12 \%$ area TN Gunung Palung terkonversi untuk dimanfaatkan masyarakat dan 5\% lahan terbuka yang perlu untuk direstorasi. Program konservasi harus tetap dilakukan walaupun telah terjadi penurunan aktivitas deforestasi di TN Gunung Palung.

\section{UCAPAN TERIMA KASIH/ ACKNOWLEDGEMENT}

Kami mengucapkan terima kasih untuk seluruh pihak yang terlibat dalam upaya konservasi di Taman Nasional Gunung Palung.

\section{DAFTAR PUSTAKA}

Alroy, J. (2017). Effects of habitat disturbance on tropical forest biodiversity. Proceedings of the National Academy of Sciences of the United States of America, 114(23), 6056-6061. https://doi.org/10.1073/pnas.161185 5114

Anderson, J. R., Hardy, E. E., Roach, J. T., \& Witmer, R. E. (1976). A Land Use and Land Cover Classification System for Use with Remote Sensor Data. United States Geological Survey Professional Paper, 964. 
Baccini, A., Goetz, S. J., Walker, W. S., Laporte, N. T., Sun, M., SullaMenashe, D., Hackler, J., Beck, P. S. A., Dubayah, R., Friedl, M. A., Samanta, S., \& Houghton, R. A. (2012). Estimated carbon dioxide emissions from tropical deforestation improved by carbon-density maps. Nature Climate Change, 2(3), 182185.

https://doi.org/10.1038/nclimate135 4

BPS Kab. Kayong Utara. (2019). Kabupaten Kayong Utara dalam Angka 2019. Badan Pusat Statistik Kabupaten Kayong Utara. https://doi.org/10.1192/bjp.111.479. 1009-a

Curran, L. M., \& Leighton, M. (2000). Vertebrate responses to spatiotemporal variation in seed production of mast-fruiting Dipterocarpaceae. Ecological Monographs, 70(1), 101-128. https://doi.org/10.1890/00129615(2000)070[0101:VRTSVI]2.0. $\mathrm{CO} ; 2$

Curran, L. M., Trigg, S. N., Mcdonald, A K., \& Astiani, D. (2004). Lowland Forest Loss in Protected Areas. Terra, 303(February), 1000-1003. https://doi.org/10.1126/science.1091 714

Dillis, C., Marshall, A. J., \& Rejmánek, M. (2017). Change in disturbance regime facilitates invasion by Bellucia pentamera Naudin (Melastomataceae) at Gunung Palung National Park, Indonesia. Biological Invasions, 19(4), 13291337.

https://doi.org/10.1007/s10530-0161345-5

Ellison, D., Morris, C. E., Locatelli, B., Sheil, D., Cohen, J., Murdiyarso, D., Gutierrez, V., Noordwijk, M. van, Creed, I. F., Pokorny, J., Gaveau, D.,
Spracklen, D. V., Tobella, A. B., Ilstedt, U., Teuling, A. J., Gebrehiwot, S. G., Sands, D. C., Muys, B., Verbist, B., ... Sullivan, C. A. (2017). Trees, forests and water: Cool insights for a hot world. Global Environmental Change, 43, 51-61. https://doi.org/10.1016/J.GLOENV CHA.2017.01.002

Fawzi, N. I. (2016). Penginderaan Jauh untuk Lingkungan dan Konservasi. Penerbit Ombak.

Fawzi, N. I., Husna, V. N., \& Helms, J. A. (2018). Measuring deforestation using remote sensing and its implication for conservation in Gunung Palung National Park, West Kalimantan, Indonesia. IOP Conference Series: Earth and Environmental Science, 149(conference 1), 012038. https://doi.org/10.1088/17551315/149/1/012038

Fawzi, N. I., \& Iswari. (2019). Hubungan Kategori Tutupan Lahan dan Suhu Permukaan Menggunakan Landsat 8. Jurnal Spasial, 6(1), 27-35.

Gaveau, D. L. A., Kshatriya, M., Sheil, D., Sloan, S., Molidena, E., Wijaya, A., Wich, S., Ancrenaz, M., Hansen, M., Broich, M., Guariguata, M. R., Pacheco, P., Potapov, P., Turubanova, S., \& Meijaard, E. (2013). Reconciling Forest Conservation and Logging in Indonesian Borneo. PLoS ONE, 8(8). https://doi.org/10.1371/journal.pone. 0069887

Grecchi, R. C., Beuchle, R., Edemir, Y., Aragão, L. E. O. C., Arai, E., Simonetti, D., \& Achard, F. (2017). An integrated remote sensing and GIS approach for monitoring areas affected by selective logging: A case study in northern Mato Grosso, Brazilian Amazon. International Journal of Applied Earth 
Observation and Geoinformation, 61, 70-80. https://doi.org/10.1016/j.jag.2017.05 .001

Guariguata, M. R., Chazdon, R. L., Denslow, J. S., Dupuy, J. M., \& Anderson, L. (1997). Structure and floristics of secondary and oldgrowth forest stands in lowland Costa Rica. Plant Ecology, 132(1), 107-120.

https://doi.org/10.1023/A:10097264 21352

Hammen, V. C., \& Settele, J. (2011). Biodiversity and the Loss of Biodiversity Affecting Human Health. In Encyclopedia of Environmental Health (pp. 353362).

Elsevier. https://doi.org/10.1016/B978-0-44452272-6.00655-3

Johnson, A. E., Knott, C. D., Pamungkas, B., Pasaribu, M., \& Marshall, A. J. (2005). A survey of the orangutan (Pongo pygmaeus wurmbii) population in and around Gunung Palung National Park, West Kalimantan, Indonesia based on nest counts. Biological Conservation, 121(4), 495-507. https://doi.org/10.1016/J.BIOCON.2 004.06 .002

Kiyono, Y., \& Hastaniah. (2000). The Role of Slash-and-Burn Agriculture in Transforming Dipterocarp Forest into Imperata Grassland (pp. 199208). https://doi.org/10.1007/978-4431-67911-0_17

Kubo, H., Wibawanto, A., \& Rossanda, D. (2019). Toward a policy mix in conservation governance: A case of Gunung Palung National Park, West Kalimantan, Indonesia. Land Use Policy, $\quad$ 88(July), 104108. https://doi.org/10.1016/j.landusepol. 2019.104108
Langner, A., Samejima, H., Ong, R. C., Titin, J., \& Kitayama, K. (2012). Integration of carbon conservation into sustainable forest management using high resolution satellite imagery: A case study in Sabah, Malaysian Borneo. International Journal of Applied Earth Observation and Geoinformation, 18, 305-312. https://doi.org/10.1016/j.jag.2012.02 .006

Latif, M. T., Othman, M., Abdullah, A. M., Khan, M. F., Ahamad, F., \& Juneng, L. (2017). Southeast Asian Forest Fires (1997/1998): El Niño as a Driver of Regional Impacts. In Brimblecombe Peter (Ed.), Air Pollution Episodes (pp. 191-225). World Scientific Publishing Europe, Ltd.

https://doi.org/10.1142/9781786343 413_0011

Lawrence, D., \& Vandecar, K. (2015). Effects of tropical deforestation on climate and agriculture. Nature Climate Change, 5(1), 27-36. https://doi.org/10.1038/nclimate243 0

Loveland, T. R., \& Irons, J. R. (2016). Landsat 8: The plans, the reality, and the legacy. Remote Sensing of Environment, 185, 1-6. https://doi.org/10.1016/j.rse.2016.07 .033

Patz, J. A., Graczyk, T. K., Geller, N., \& Vittor, A. Y. (2000). Effects of environmental change on emerging parasitic diseases. International Journal for Parasitology, 30(12-13), 1395-1405. https://doi.org/10.1016/S00207519(00)00141-7

Phillips, O. L. (1997). The changing ecology of tropical forests. Biodiversity and Conservation, 6(2), 291-311. 
https://doi.org/10.1023/A:10183524 05482

Posa, M. R. C. (2011). Peat swamp forest avifauna of Central Kalimantan, Indonesia: Effects of habitat loss and degradation.

Biological Conservation, 144(10), 2548-2556. https://doi.org/10.1016/J.BIOCON.2 011.07.015

Setiawan, E., \& Sofian, D. (2018). Gunung Palung National Park Living in Harmony. Gunung Palung National Park.

Shvidenko, A. (2008). Deforestation. Encyclopedia of Ecology, 29-34. https://doi.org/10.1016/B978-0-44463768-0.00586-2

Swamy, L., Drazen, E., Johnson, W. R., \& Bukoski, J. J. (2018). The future of tropical forests under the United Nations Sustainable Development Goals. Journal of Sustainable Forestry, 37(2), 221-256. https://doi.org/10.1080/10549811.20 17.1416477

Taufik, M., Torfs, P. J. J. F., Uijlenhoet, R., Jones, P. D., Murdiyarso, D., \& Van Lanen, H. A. J. (2017). Amplification of wildfire area burnt by hydrological drought in the humid tropics. Nature Climate Change, 7(6), 428-431. https://doi.org/10.1038/nclimate328 0

Tricahyono, K., Riyono, J. N., \& Latifah, S. (2016). Land Cover Change Analysis by Using Landsat ETM7+ Image in Gunung Palung National Park Residing in The District of North Kayong West Kalimantan Province. Jurnal Hutan Lestari, 4(4), 401-408.

Tsujino, R., Yumoto, T., Kitamura, S., Djamaluddin, I., \& Darnaedi, D. (2016). History of forest loss and degradation in Indonesia. Land Use Policy, 57, 335-347. https://doi.org/10.1016/j.landusepol. 2016.05.034

van der Werf, G. R., Morton, D. C., DeFries, R. S., Olivier, J. G. J., Kasibhatla, P. S., Jackson, R. B., Collatz, G. J., \& Randerson, J. T. (2009). CO2 emissions from forest loss. Nature Geoscience, 2(11), 737738.

https://doi.org/10.1038/ngeo671

van Dijk, A. I. J. M., van Noordwijk, M., Calder, I. R., Bruijnzeel, S. L. A., Schellekens, J. A. A. P., \& Chappell, N. A. (2009). Forest-flood relation still tenuous - Comment on 'Global evidence that deforestation amplifies flood risk and severity in the developing world'by C. J. A. Bradshaw, N.S. Sodi, K. S.-H. Peh and B.W. Brook. Global Change Biology, 15(1), 110-115. https://doi.org/10.1111/j.13652486.2008.01708.x

Wang, K., Franklin, S. E., Guo, X., \& Cattet, M. (2010). Remote sensing of ecology, biodiversity and conservation: a review from the perspective of remote sensing specialists. Sensors (Basel, Switzerland), 10(11), 9647-9667. https://doi.org/10.3390/s101109647

Webb, K., Jennings, J., \& Minovi, D. (2018). A community-based approach integrating conservation, livelihoods, and health care in Indonesian Borneo. The Lancet Planetary Health, 2, S26. https://doi.org/10.1016/S25425196(18)30111-6

Yoshikura, T., Amano, M., \& Anshari, G. Z. (2018). Exploring Potential of REDD+ Readiness with Social Safeguard through Diverse Forest Use Practices in Gunung Palung National Park in West Kalimantan, Indonesia. Open Journal of Forestry, 08(02),

141-154. 
https://doi.org/10.4236/ojf.2018.820 10

Yoshikura, T., Amano, M., Chikaraishi, H., Supriyanto, B., \& Wardhana, D. (2016a). Evaluation of Appropriate Identification of Deforestation Agents and Drivers for Designing REDD+ Readiness Activities through an Examination of the Area around Gunung Palung National Park, Indonesia. Open Journal of Forestry, 06(02), 106-122. https://doi.org/10.4236/ojf.2016.620

10

Yoshikura, T., Amano, M., Wardhana, D., \& Supriyanto, B. (2016b). Identifying the agents and drivers of deforestation: an examination around Gunung Palung National Park, West Kalimantan, Indonesia. International Journal of Agricultural Resources, Governance and Ecology, 12(4), 327-343.

https://doi.org/10.1504/ijarge.2016.1 0001702

Zamzani, F., Onda, N., Yoshino, K., \& Masuda, M. (2009). Deforestation and agricultural expansion processes in Gunung Palung National Park, West Kalimantan, Indonesia. Jurnal Manajemen Hutan Tropika, 15(1), 24-31. 